\title{
IN VITRO EVALUATION OF THE MARGINAL INTEGRITY OF MONOLITHIC CERAMIC CROWNS UTILIZING DIFFERENT MACHINABLE BLOCKS FABRICATED FOR MINIMALLY INVASIVE VERTICAL PREPARATION DESIGNS
}

\author{
Marwa M. Wahsh" and Doaa T.S. Taha ${ }^{* *}$
}

\begin{abstract}
Purpose: This study aimed to evaluate the marginal adaptation of monolithic ceramic crowns with minimally invasive vertical preparation design utilizing different machinable blocks.

Materials and method: Stainless steel die was designed to simulate all ceramic crown preparation with $0.1 \mathrm{~mm}$ featheredge margin. A total of 50 monolithic crowns were constructed from five different tested ceramic materials; 10 crowns from each material: Group EX for lithium disilicate ceramic (IPS. emax), group VE for polymer infiltrated ceramic (Vita Enamic), group CD for zirconia-reinforced lithium silicate ceramic (glazed Celtra Duo), group TZ for translucent zirconia (inCoris TZI) and group HTZ for high translucent zirconia (Ceramill zolid zirconia). After surface treatments, adhesive cementation and thermocycling, stereomicroscope with a digital camera and image analysis software were used to measure the vertical gaps between the cervical margin of the crown and the outer end of the finish line. The mean vertical gap for each crown was then calculated.
\end{abstract}

Results: High translucent zirconia crowns (group HTZ) showed the lowest mean marginal gap value $(29.04 \pm 7.77 \mu \mathrm{m})$ with statistically significant difference than all the other tested materials. While e.max crowns EX showed the highest mean marginal gap value $(95.37 \pm 13.84 \mu \mathrm{m})$ which was statistically significant from all the other tested groups.

Conclusion: High translucent zirconia crowns showed superior marginal adaptation compared to all other tested materials, while lithium disilicate crowns showed the least accuracy. For the all tested materials, the marginal vertical gap readings recorded in this study were within the limits of clinically acceptable standards.

KEY WORDS: Monolithic crowns, all ceramic, hybrid ceramic, marginal adaptation, vertical preparation

\footnotetext{
* Associate Professor of Fixed Prosthodontics Department, Faculty of Dentistry, Ain-Shams University, Cairo, Egypt.

** Lecturer of Fixed Prosthodontics Department, Faculty of Dentistry, Ain-Shams University, Cairo, Egypt.
} 


\section{INTRODUCTION}

Tooth preparation for a prosthetic crown has been always considered invasive in nature since it leads to inevitable irreversible loss of tooth hard tissues. In the case of tooth preparation with vital dental pulp there is always the risk of irritation, inflammation, necrosis, and endodontic treatment in the future. A variety of attempts have been suggested throughout years to develop methods of tooth preparation with minimum loss of sound tooth structure. ${ }^{(1)}$ However, since marginal integrity plays a substantial role in the longevity and long-term success of restorations, it would be of great importance that these preparation approaches would not jeopardize adequate marginal fit and emergency profile. ${ }^{(2)}$

Generally, there are two types of preparation: preparation with finish lines called horizontal preparation, and preparation without finish lines described as vertical or feather-edge preparation. (3) The use of shoulder and chamfer as horizontal finish lines for the preparation has been commonly implemented in practice attributed to their presumed advantages in avoiding overhangs and over-contouring of the restorations leading to better lab-clinician communication and enhanced workflow. ${ }^{(4)}$ In the past, vertical preparation was usually indicated for periodontally involved abutments for fixed prostheses as this approach may be more conservative than horizontal preparation under different clinical situations. ${ }^{(3)}$ However, some drawbacks of vertical preparation have been noticed like overhangs, over-contouring, lack of control on marginal seal and integrity, unpredictable tissue healing and difficulties in removing excess cement. ${ }^{(5)}$ In addition, the difficulty to locate these tapered thin margins based on data obtained from gingival tissue by laboratory technician and the liability to chipping fracture of the restorations have always complicated the decision to use vertical preparation designs. ${ }^{(6)}$

However, since the ultimate goal of reconstructive dentistry recently is to obtain excellent esthetic results while simultaneously respecting the biological structures, shifting toward a more conservative preparation approach has been widely emerging back. ${ }^{(7)}$ Currently, both clinicians and technicians have versatile range of choices for different ceramic materials and fabrication techniques that can enable adopting the minimally invasive conservative approach with increased predictability. ${ }^{(8)}$ The rapid development of ceramic systems empowered the treatment of teeth in both the anterior and posterior areas, with the primary objectives of properly restoring form, function and esthetic excellence without the presence of metal. Computer aided design/ Computer aided manufacturing (CAD/CAM) systems have dramatically enhanced dentistry with the introduction of new systems demonstrating expanded capabilities, improved quality, and wide range of applications. ${ }^{(9)}$

Among the dental ceramics, both lithium disilicate, zirconium dioxide and their derivatives have emerged widely because of their biological, mechanical and optical properties, which has certainly accelerated their routine use in CAD/CAM technology for different types of prosthetic solutions. New zirconia compositions with optimized esthetic properties have emerged due to the fast-growing technology in zirconia manufacturing. ${ }^{(10)}$

Materials with mechanical properties like those of sound teeth have been introduced recently and proved enhanced reliability of the restorative system. An example is zirconia reinforced lithium silicate or ZLS, which is a new addition to the lithium ceramic family with the addition of $10 \%$ by weight zirconia to the composition offering "a homogeneous, fine crystalline structure with an average crystal size of $0.5 \mu \mathrm{m}$ compared to the needle-shaped crystals with an average size of 1.5 $\mu \mathrm{m}$ found in the lithium disilicate ceramic." (11-13) Another example are Hybrid ceramics which are polymer infiltrated ceramic material that combines the properties of ceramic and polymer. It consists of a hybrid structure with two interpenetrating networks of dominating ceramic and a reinforcing composite forming the so-called double network hybrid ceramic material. ${ }^{(14)}$ One of the main advantages 
of this material as a new dental restorative material is the reasonable brittleness index which makes the material a suitable CAD/CAM candidate. ${ }^{(13,15)}$

It is worth mentioning that high degree of discrepancy in marginal fit is observed for these different ceramic systems taking in consideration important factors like finish line design, cement type and the type of material used. ${ }^{(16,17)}$ Feather edge minimally invasive finish line has already been tested in several in vitro studies and in vivo trials with zirconia crowns. ${ }^{(18)}$ However, further research is needed to investigate the use of feather-edge margins with lithium disilicate ceramics and other available ceramic materials in the market.

The purpose of this in vitro study was to assess the marginal adaptation of monolithic ceramic crowns fabricated for minimally invasive vertical preparation design utilizing different machinable ceramic blocks. The null hypothesis tested was that there is no difference in the marginal adaptation between the ceramic crowns fabricated for minimally invasive vertical preparation designs using the different tested materials.

\section{MATERIALS AND METHODS}

A stainless-steel master die was prepared by a milling machine to simulate all ceramic full coverage crown preparation of a maxillary premolar.
The steel die was machined with height $5.5 \mathrm{~mm}, 12$ degrees total occlusal convergence angle and flat occlusal surface. Feather edge margin design 0.1 $\mathrm{mm}$ in thickness was prepared as shown in (Fig.1 a,b). Four equidistant marks were engraved on each die to orient the stereomicroscope for marginal gap measurement. An occlusal bevel was prepared at the occluso-axial line angle of the buccal surface of the die for exact repositioning of the crowns during cementation.

Impression of the master die was taken with a silicone duplicating material (Dupliflex, Protechno, Spain) using perforated plastic tube.As recommended by the manufacturer, the two components of the silicone duplicating material were mixed with equal proportions (1:1) for 30 seconds until uniformly colored dough was obtained. The mixing was done slowly to avoid the air trapping then it was put in the plastic tubes and seated on the metal die until the material was set. For the measurement of vertical marginal gap, epoxy resin dies were fabricated (Fig.1c), the impression was poured using a nonshrink epoxy resin material (Kemapoxy 150, CMB, Egypt). The liquid components $\mathrm{A}$ (resin) and $\mathrm{B}$ (hardener) were mixed in ratio $2 \mathrm{~A}: 1 \mathrm{~B}$ by weight to a homogenous color for 3 minutes on the vibrator and introduced inside the impression slowly with a blunted probe on the vibrator to avoid air entrapment.

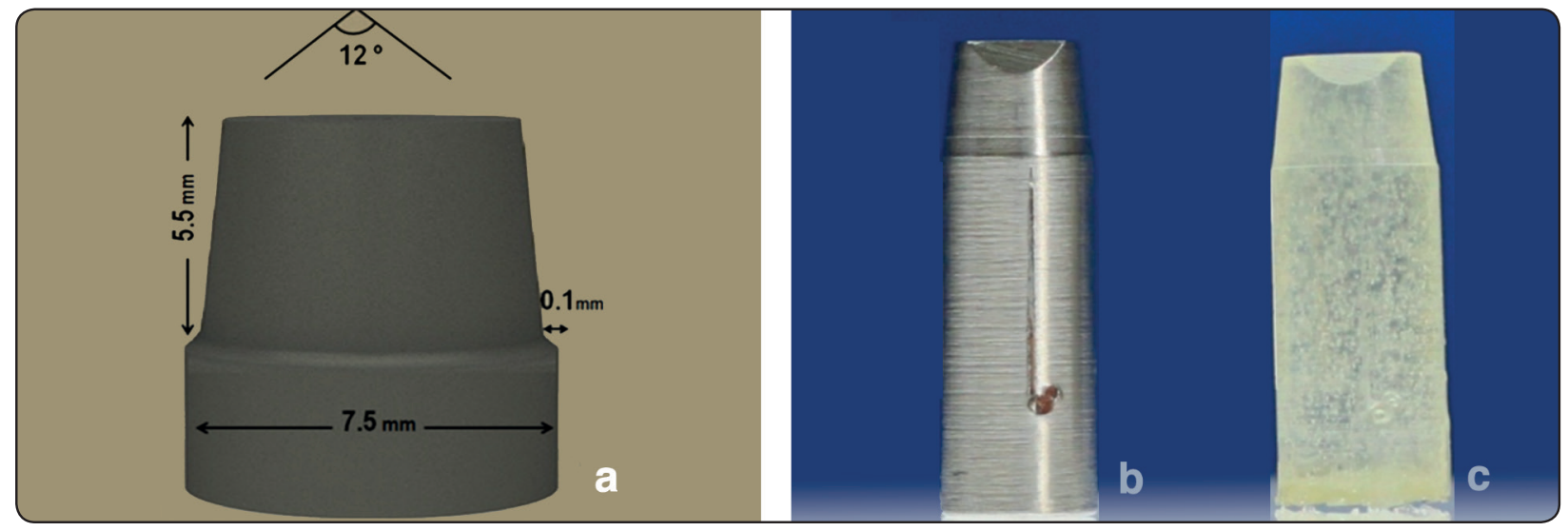

Fig. (1) a) diagram showing the dimensions of the master die, b) master steel die with $0.1 \mathrm{~mm}$ feather edge vertical preparation design, c) duplicated resin die 
Impressions were removed after 24 hours to ensure that epoxy resin dies had their maximum hardness. For the ease of identification, serial numbers were engraved on the bottom of the dies.

The CEREC AC system (Sirona, Germany) were used for fabrication of the ceramic crowns after scanning the epoxy dies with Omnicam. CEREC 3D Software (version 4.3) was used for designing standardized ceramic crowns. A total of 50 monolithic all ceramic crowns were constructed from five different tested ceramic materials; 10 crowns from each material: Group EX for lithium disilicate ceramics (IPS. emax), group VE for polymer infiltrated ceramics (Vita Enamic), group $\mathrm{CD}$ for zirconia-reinforced lithium silicate ceramics (glazed Celtra Duo), group TZ for translucent zirconia (inCoris TZI) and group HTZ for super high translucent zirconia (ceramill zolid zirconia). Tested materials are listed in Table 1. EX, VE, $\mathrm{CD} \& \mathrm{TZ}$ crowns were milled using Cerec MCXL milling machine. EX crowns were crystallized in a compatible ceramic furnace (Programat CS4, Ivoclar Vivadent, United States) at $840^{\circ} \mathrm{C}$. Polishing was performed according to each manufacturer recommendation; VE crowns were polished using VITA ENAMIC Polishing Set, Celtra duo CD crowns were cleaned with a steam cleaner and Celtra glaze (Dentsply Sirona ,United States) was mixed with liquid and applied to the crown surface using a brush, then glaze firing was done in in a compatible ceramic furnace (Programat CS4, Ivoclar Vivadent,) at $820^{\circ} \mathrm{C}$. Translucent zirconia crowns were milled with an oversize of approximately $25 \%$ to compensate for the later sintering shrinkage and then sintered for approximately 90 minutes in inFire HTC speed furnace (Sirona, Germany) at a sintering temperature of $1540^{\circ} \mathrm{C}$. For the fabrication of $\mathrm{HTZ}$ crowns, STL file of the crown design was transferred to the Cerec MCX5 milling machine to be milled in an oversize dimension with the green stage zirconia blanks (Ceramill@ Zolid HT+ White; Amann Girrbach AG, Austria) in order to compensate for the dimensional shrinkage of 25-30\%. They were then sintered in a furnace (Ceramill ${ }^{\circledR}$ Therm 3; Amann Girrbach AG, Austria), according to the manufacturer's recommended firing parameters, at a temperature of $1450^{\circ} \mathrm{C}$ for a 120 -minute holding period, which concluded with a sintering process that took a total of 7.5 hours for each zirconia crown. After fabrication, all the restorations were tried on their corresponding resin dies and checked for complete seating.

For adhesive cementation of the crowns, each group of crowns was cemented following the manufacturer recommendations. The internal surfaces of the zirconia crowns (TZ, HTZ) were sandblasted to provide micro-retentive roughening by the one-way blasting process with $50 \mu \mathrm{m}$ corundum $\left(\mathrm{Al}_{2} \mathrm{O}_{3}\right)$ and pressure 2.5 bar. Etching of the bonding surfaces of the crowns was done using hydrofluoric acid gel $4.5 \%$ (Porcelain etch, Ultradent Products, UT, United Stated) for 20, 60, 30 seconds for EX, VE and CD crowns, respectively. The crowns were then rinsed thoroughly and dried with oil free air. The surfaces were then silanized by a primer (Porcelain silane, Ultradent Products, UT, United Stated) and left to react for 60 seconds. Selfadhesive resin cement (RelyX Unicem2 Automix, 3M ESPE, Seefeld, Germany) was applied using the automix tip to the fitting surface of the crowns which were placed on their relevant dies by static finger pressure then axially loaded with a $1 \mathrm{~kg}$ load using a specially designed device. The crowns were left under the static load for 5 minutes then exposed to a brief light curing for only 2 seconds. The excess cement was removed with a scaler, and then light curing was done for 20 seconds for each side. Thermocycling was performed for 5000 cycles between $5^{\circ} \mathrm{C}$ and $55^{\circ} \mathrm{C}$ water (Dwell time 30 seconds) for all the specimens.

For measurements of the cervical vertical marginal discrepancies, a specially designed metal jig was used to secure the specimens during the measurements. For each specimen, four 
TABLE (1) The materials tested in this study:

\begin{tabular}{|c|c|c|c|c|c|}
\hline Group & Material & Manufacturer & Lot Number & Ceramic type & Chemical composition \\
\hline EX & e.max CAD & $\begin{array}{l}\text { Ivoclar } \\
\text { Vivadent,United } \\
\text { States }\end{array}$ & T50232 & $\begin{array}{l}\text { Lithium disilicate glass } \\
\text { ceramic }\end{array}$ & $\begin{array}{l}\mathrm{SiO}_{2}, \mathrm{Li}_{2} \mathrm{O}, \mathrm{K}_{2} \mathrm{O}, \mathrm{P}_{2} \mathrm{O}_{5}, \\
\mathrm{ZrO}_{2}, \mathrm{ZnO}, \mathrm{Al}_{2} \mathrm{O}_{3}, \mathrm{MgO} \text { and } \\
\text { coloring oxides. }\end{array}$ \\
\hline VE & Vita Enamic & $\begin{array}{l}\text { VITA-Zahnfabrik, } \\
\text { Germany }\end{array}$ & 100022 & $\begin{array}{l}\text { Polymer infiltrated } \\
\text { ceramic }\end{array}$ & $\begin{array}{l}\mathrm{SiO}_{2}, \mathrm{Al}_{2} \mathrm{O}_{3}, \mathrm{Na}_{2} \mathrm{O}, \\
\mathrm{K}_{2} \mathrm{O}, \mathrm{B}_{2} \mathrm{O}_{3}, \mathrm{CaO}, \mathrm{TiO}_{2}, \\
\text { TEG-DMA, UDMA }\end{array}$ \\
\hline $\mathrm{CD}$ & Celtra Duo & $\begin{array}{l}\text { Dentsply, United } \\
\text { States }\end{array}$ & 16004647 & $\begin{array}{l}\text { Zirconia-reinforced } \\
\text { lithium silicate ceramic }\end{array}$ & $\begin{array}{l}\mathrm{SiO}_{2}, \mathrm{Li}_{2} \mathrm{O}, \mathrm{ZrO}_{2}, \mathrm{P}_{2} \mathrm{O}_{5}, \\
\mathrm{Al}_{2} \mathrm{O}_{3}, \mathrm{~K}_{2} \mathrm{O}, \mathrm{CeO}_{2} \text {, pigments }\end{array}$ \\
\hline $\mathrm{TZ}$ & inCoris TZI & Sirona, Germany & 2011271569 & Translucent zirconia & $\begin{array}{l}\mathrm{ZrO}_{2}+\mathrm{HfO}_{2}+\mathrm{Y}_{2} \mathrm{O}_{3} \geq 99.0 \% \\
\mathrm{Y}_{2} \mathrm{O}_{3} 5.6 \%, \mathrm{Al}_{2} \mathrm{O}_{3} \leq 0.35 \% \\
\text { Other oxides } \leq 0.2 \%\end{array}$ \\
\hline HTZ & $\begin{array}{l}\text { Ceramill } \\
\text { Zolid } \\
\text { HT+ White }\end{array}$ & $\begin{array}{l}\text { Amann Girrbach AG, } \\
\text { Austria }\end{array}$ & 1906001 & High translucent zirconia & $\begin{array}{l}\mathrm{ZrO}_{2}+\mathrm{HfO}_{2}+\mathrm{Y}_{2} \mathrm{O}_{3} \geq 99.0 \\
\mathrm{Y}_{2} \mathrm{O}_{3} 6.7-7.2, \mathrm{HfO}_{2} \leq 5 \\
\mathrm{Al}_{2} \mathrm{O}_{3} \leq 0.5 \text {,other oxides } \leq 1\end{array}$ \\
\hline
\end{tabular}

stereomicrographs, at the four predetermined marks, were captured by a digital camera (DP10, Olympus, Japan) mounted on a Zoom Stereo microscope (SZPT, Olympus, Japan) at a magnification 13.5X. Images were then transferred to the computer system for analysis. Using the image analysis software (Image J, 1.46r, NIH, USA) phase analysis was calculated automatically to measure the vertical gaps between the cervical margin of the crown and the outer end of the finish line at 5 different points in each stereomicrograph. (Figs. 2). Therefore, the measurements were carried out at 20 points for each crown. The mean vertical gap (in microns) for each specimen was then calculated and tabulated for statistical analysis.

Initially descriptive statistics for each group were held. Shapiro-Wilk test was used to assess data normality and data was assumed normally distributed. One-Way ANOVA test was used to examine effect of material on the marginal adaptation. P-value is the level of significance, if $P>0.05$ : Nonsignificant (NS), $P \leq 0.05$ : Significant (S).

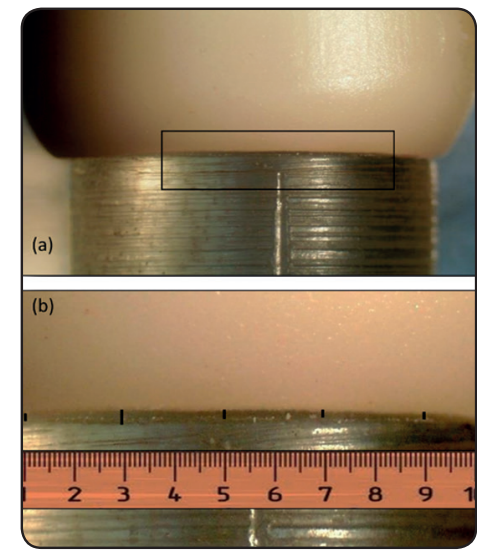

Fig. (2) Example on marginal gap measurements A: area of stereomicrograph around predetermined mark; B: five equidistant marks for measurements (with a virtual ruler).

\section{RESULTS}

Descriptive statistics (mean and standard deviations) of marginal gap results measured $(\mu \mathrm{m})$ for the tested groups are presented in (Table 2) (Fig.3). The results of one-way ANOVA showed that the type of material had a statistically significant effect on the marginal adaptation of monolithic ceramic crowns fabricated for minimally invasive vertical preparation designs. 
High translucent zirconia crowns (group HTZ) showed the lowest mean marginal gap value (29.04 $\pm 7.77 \mu \mathrm{m}$ ) with statistically significant difference than translucent zirconia crowns TZ $(74.9 \pm 13.22 \mu \mathrm{m})$, Vita Enamic crowns VE $(71.67 \pm 11.58 \mu \mathrm{m})$ and Celtra Duo crowns CD $(64.61 \pm 10.78 \mu \mathrm{m})$. While Emax crowns EX showed the highest mean marginal gap value $(95.37 \pm 13.84 \mu \mathrm{m})$ which was statistically significant from all the other tested groups.

TABLE (2) Comparison between marginal gap results (mean and standard deviation) in $(\mu \mathrm{m})$ for the tested groups:

\begin{tabular}{|c|c|c|}
\hline Group & Mean $(\mu \mathrm{m})$ & Standard deviation \\
\hline EX & $95.37^{\mathrm{c}}$ & 13.84 \\
\hline VE & $71.67^{\mathrm{b}}$ & 11.58 \\
\hline CD & $64.61^{\mathrm{b}}$ & 10.78 \\
\hline TZ & $74.9^{\mathrm{b}}$ & 13.22 \\
\hline HTZ & $29.04^{\mathrm{a}}$ & 7.77 \\
\hline
\end{tabular}

*Different superscript letters indicate significance

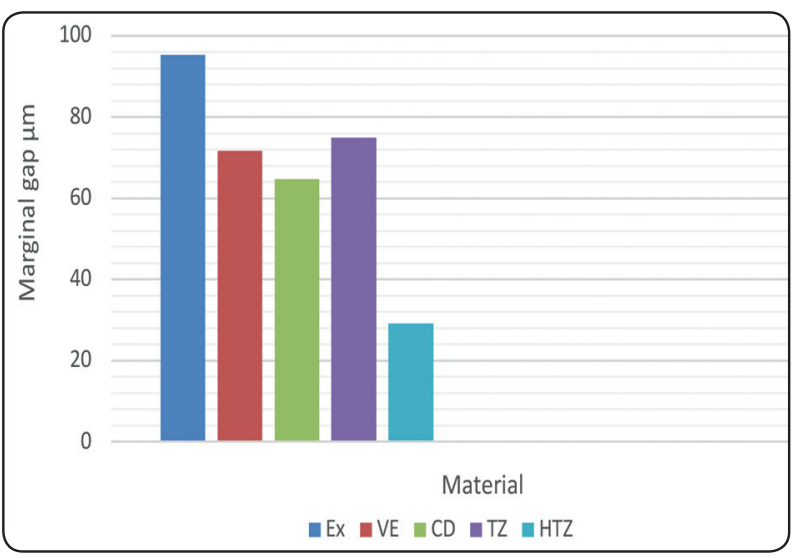

Fig. (3) Column chart representing mean marginal gap values $(\mu \mathrm{m})$ for the tested materials

\section{DISCUSSION}

Conservative dentistry faces a challenge of attaining optimal esthetics and at the same time minimizing its adverse effects on the biological structures involved. ${ }^{(19)}$ A variety of CAD/CAM materials which differ in chemical composition and indications are available in the dental market with variable indications. ${ }^{(20)}$

The importance of adaptation between the tooth and the restoration has been recognized as a crucial factor affecting the long-term success of restorations. (21) Marginal gap values of ranging from 100-200 $\mu \mathrm{m}$ have been reported in previous studies to be clinically acceptable for cemented restorations. (22, ${ }^{23)}$ Excessive marginal gaps may affect periodontal tissues, increase dental plaque retention, favor the development of recurrent caries or pulp lesions, and lead to bone resorption. ${ }^{(24)}$

Either shoulder or chamfer finish lines can be selected for all-ceramic crowns bonded to prepared teeth. Recommended finish line depths for allceramic crowns have ranged from 0.5 to $1.0 \mathrm{~mm} .{ }^{(25)}$ Recently, feather edge margins for zirconia crowns have been evaluated in vitro as a less invasive preparation design that allows acceptable clinical performance. ${ }^{(26)}$ A study by Reich et al ${ }^{(27)}$ indicated that anterior zirconia crowns with feather-edged preparations presented a promising alternative to traditional finish lines. Clinical performance results suggest that for zirconia crowns, feather-edge margins allow clinical performance similar to that reported with other margin designs ${ }^{(26,28-30)}$

However, there is not enough information in literature regarding the best $\mathrm{CAD} / \mathrm{CAM}$ material to be used with vertical preparations or feather-edge margins. The aim of this in vitro study was to assess the marginal adaptation of different monolithic ceramic crowns bonded to feather edge margin, targeting to present a minimally invasive prosthetic approach where a full crown is required, guided by the study of Cortellini et al ${ }^{(18)}$. In a study by Cömlekoglu et al ${ }^{(31)}$, it was concluded that the 
feather-edge type of finish line exhibited the least marginal discrepancy. This was attributed to the fact that the more the restoration margin ends with an acute angle, the shorter the distance between the restoration margin and the tooth which had been described previously by Schillinburg et al. ${ }^{(32)}$

In the present study, all the procedures were carried out by the same operator for the purpose of standardization. Each stainless steel die was machined with height $5.5 \mathrm{~mm}$ and $12^{\circ}$ total occlusal convergence angle as recommended by Goodacre et al ${ }^{25)}$ for the preparation of an all-ceramic restoration. An occlusal bevel was prepared at the occluso-axial line angle in one side of the die for exact repositioning of the crowns during cementation.

Epoxy resin material was selected as a die material in the present study on which the test specimens were cemented for investigating their marginal adaptation since its modulus of elasticity is similar to the reported modulus of human dentin and they are easily available and their dimensions can be standardized. ${ }^{(33)}$ The use of extracted natural teeth as specimens has been found to simulate clinical conditions more closely than resin abutments. However, standardization of natural teeth is difficult because of several factors such as age, anatomy, size, shape and storage time after extraction. ${ }^{(34)}$

The assessment of the marginal adaptation of the crowns was performed using stereomicroscope. Direct viewing with external measurements which was used in this study has the advantage of not being invasive and, therefore, applicable to clinical practice but it is difficult to repeat the measurements from an identical angle and to distinguish the actual marginal gap from its projection. ${ }^{(35)}$ The vertical cervical marginal gap measurement was selected as the most frequently used to quantify the accuracy of fit of a restoration. ${ }^{(36)}$

The results of the current study revealed that high translucent zirconia crowns (group HTZ) showed the lowest mean marginal gap value
$(29.04 \pm 7.77 \mu \mathrm{m}) \quad$ with statistically significant difference compared to other test groups. Marginal accuracy of CAD/CAM restorations can be affected by several factors including: scanning technique, designing software and milling process. Carbide milling tools were used to mill zirconia blocks while diamond tools were used for other CAD blocks. Also, the zirconia blanks were dry milled while other blocks were wet milled which could explain the difference in marginal gap values recorded. In addition, the pre-sintered state is less hard than other ceramic materials, it can be milled with less pressure and greater ease offering the advantage of producing thin edge design due to its excellent toughness and strength and ease of milling. ${ }^{(37)}$

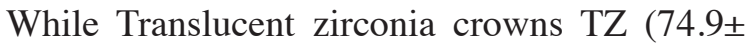

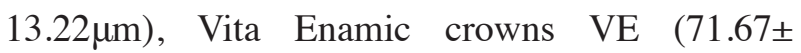
$11.58 \mu \mathrm{m})$ and Celtra Duo crowns CD (64.61土 $10.78 \mu \mathrm{m})$ mean marginal gaps were statistically insignificant. Vita Enamic crowns are milled in their final shape and no additional processing is required and does not entail any dimensional changes. As for Celtra Duo, the microstructure of the material is claimed by the manufacturer to present high edge stability providing acceptable margins. ${ }^{(12)}$ In addition, variations in mean gap values recorded for both types of zirconia tested could be due to the different number of milling axis of both systems (4-axis milling unit of the Cerec MCXL and the 5-axis unit of the Cerec MCX5). Bosch et al. (38) stated that five-axis milling produces high trueness and permits a more effective milling of surfaces close to the insertion axis and a better outcome can be produced with steep walls and small angles.

Moreover, e.max CAD crowns EX showed the highest mean marginal gap value $(95.37 \pm 13.84 \mu \mathrm{m})$ which was statistically significant compared to all the other tested groups. The differences could be due to the variations in materials' properties. For example, Vita Enamic blocks are softer than lithium disilicate CAD/CAM blocks, that can be milled 
faster producing less wear of the milling burs. This came in accordance with previous studies by Farid

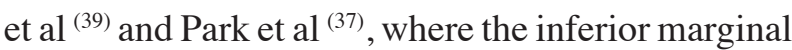
fit was attributed to the dimensional changes that occur during crystallization firing of e.max CAD. The authors proposed that as e.max CAD is weaker than zirconia, which makes it more vulnerable to dimensional changes taking place during firing and compromising the marginal fit of the milled restorations.

The findings can also be explained by the variable machinability of the different materials. In a previous study it was reported that the CEREC TM system (Sirona Dental Systems, Bensheim, Germany) can produce restorations with different marginal angles (shoulder, chamfer or bevel) with clinically acceptable marginal gaps. However, the integrity of the margins is not necessarily the same. ${ }^{(40)}$ Consequently the machinability of the chosen material can influence the integrity of a minimally designed restoration. The machinability of a material can be measured with the calculation of its brittleness index (BI) and marginal chipping factor (CF). In a study by Tsitrou et al ${ }^{(40)}$ to measure the machinability of different materials, it was concluded that machinable lithium disilicate (IPS e.max CAD) demonstrated the highest $\mathrm{BI}$ and $\mathrm{CF}$ and it doesn't represent a preferred candidate when a minimal preparation design is desired, as it would result in a restoration with high chipping factor which would compromise its marginal fit. Another possible justification for the results may be that the thin margins of the brittle glass materials is the most difficult to mill and that the milling instruments pressure and the material resistance might cause fractures at the margin. ${ }^{(41)}$

Nonetheless, despite of the statistical differences among the various groups in the current study, the marginal gap values of monolithic ceramic crowns were all within the range of clinical acceptability. From the discussed results, the null hypothesis of the present study was rejected, as there were significant differences in the marginal adaptation of single crowns constructed from different monolithic ceramic materials bonded to minimally invasive vertical preparation design.

Further studies on natural extracted teeth and randomized controlled clinical trials, for evaluation of the marginal adaptation of different monolithic ceramic crowns are suggested to assess the longterm success of ceramic crowns made with different margin designs.

\section{CONCLUSION}

Within the limitations of this in vitro study, the following conclusions could be drawn:

1. High translucent zirconia crowns showed superior marginal adaptation compared to all other tested materials, while lithium disilicate crowns showed the least accuracy.

2. For all tested materials, the marginal vertical gap readings recorded in this study were within the limits of clinically acceptable standards.

\section{REFERENCES}

1. Tripathi S, Amarnath GS, Sharma A, Choudhary S. Effect of Preparation Taper, Height and Marginal Design Under Varying Occlusal Loading Conditions on Cement Lute Stress: A Three Dimensional Finite Element Analysis. J Indian Prosthodont Soc 2014; 14:110-118.

2. Beuer F, Aggstaller H, Edelhoff D, Gernet W, Sorensen J. Marginal and internal fits of fixed dental prostheses zirconia retainers. Dent Mater 2009; 25: 94-102.

3. Loi I, Di Felice A. Biologically oriented preparation technique (BOPT): a new approach for prosthetic restoration of periodontally healthy teeth. Eur J Esthet Dent. 2013;8:10-23.

4. Ramos RM, Clark D, Mazza M, Venuti P, Maiolino M, Kopanja S, Cirimpei V, Tawfik AA, Bordonali D, Acatrinei B, Sutradhar JC. The shoulderless approach a new rationale in prosthetic dentistry. Tomorrow Tooth J. 2017;1:1-29.

5. Shillingburg Jr HT, Hobo S, Fisher DW. Preparation design and margin distortion in porcelain-fused-to-metal restorations. J Prosthet Dent 1973;29(3):276-84. 
6. Kasem AT, Sakrana AA, Ellayeh M, Özcan M. Evaluation of zirconia and zirconia-reinforced glass ceramic systems fabricated for minimal invasive preparations using a novel standardization method. J Esthet Dent 2020 Feb 3.

7. Ozkan Y, Aslan Y. Anterior esthetic restorations using minimally invasive techniques. J Dent Oral Biol. 2017; 2:1074.

8. Edelhoff D, Brix O. All-ceramic restorations in different indications: a case series. J Am Dent Assoc 2011; 142:14-19.

9. Persson AS, Andersson M, Oden A, Sandborgh-Englund G. Computer aided analysis of digitized dental stone replicas by dental CAD/CAM technology. Dent Mater 2008; 24:1123-30.

10. Kontonasaki E, Giasimakopoulos P, Rigos AE. Strength and aging resistance of monolithic zirconia: an update to current knowledge. Jpn Dent Sci Rev. 2020 1;56(1):1-23.

11. Fasbinder DJ. Chairside CAD/CAM - an overview of restorative material options. Inside Dentistry. 2012; $8: 58-65$.

12. Helvey GA. The expansion of millable materials - new additions to the market increase patient-care options. Inside Dental Technology 2014;5(1).

13. Taha D, Spintzyk S, Sabet A, Wahsh M, Salah T. Assessment of marginal adaptation and fracture resistance of endocrown restorations utilizing different machinable blocks subjected to thermomechanical aging. Journal of Esthetic and Restorative Dentistry. 2018 Jul;30(4).

14. Dirxen C, Blunck U, Preissner S. Clinical performance of a new biomimetic double network material. Open Dent J 2013;7:118-122.

15. He LH, Swain M. A novel polymer infiltrated ceramic dental material. Dent Mater 2011;27(6):527-534.

16. Futoshi K, Takayuki I, Kazuhisa K, Hideo M. Marginal and Internal Adaptation of Zirconium Dioxide Ceramic Copings and Crowns with Different Finish Line Designs. Dent Mater J 2007: 26(5): 659-664.

17. Esther G, Odont, Maria J, Med, Odont, Benjamin S, Odont, Jose F, Med. A comparison of the marginal vertical discrepancies of zirconium and metal ceramic posterior fixed dental prostheses before and after cementation. J Prosthet Dent 2009; 102:378-84.
18. Cortellini D, Canale A. «Bonding Lithium Disilicate Ceramic to Feather-Edge Tooth Preparations: A Minimally Invasive Treatment Concept.» J Adhes Dent 2012:14:7.

19. Ritter RG. Conservative interdisciplinary dentistry: a digital approach to an analog problem. Dentistry Today 2016;35:92-94.

20. Gracis S, Thompson VP, Ferencz JL, Silva NR, Bonfente EA. A new classification system for all-ceramic and ceramic-like restorative materials. Int $\mathrm{J}$ Prosthodont $2015 ; 28: 227-35$.

21. Lins L, Bemfica V, Queiroz C, Canabarro A. In vitro evaluation of the internal and marginal misfit of CAD/ CAM zirconia copings. J Prosthet Dent 2015;113:205-11.

22. Renne W, McGill ST, Forshee KV, DeFee MR, Mennito AS. Predicting marginal fit of CAD/CAM crowns based on the presence or absence of common preparation errors. J Prosthet Dent 2012;108:310-315.

23. Yeo IS, Yang JH, Lee JB. In vitro marginal fit of three allceramic crown systems. J Prosthet Dent 2003;90:459-464.

24. Rodrigo S, Mutlu M, Pavanelli A, Buso L. Marginal and Internal Discrepancies Related to Margin Design of Ceramic Crowns Fabricated by a CAD/CAM System, J Prosthodont 2011; 1-7.

25. Goodacre CJ, Campagni WV, Aquilino SA. Tooth preparations for complete crowns: An art form based on scientific principles, J Prosthet Dent 2001;85:363-76.

26. Poggio C, Dosoli R, Ercoli C. A retrospective analysis of 102 zirconia single crowns with knife-edge margins, J Prosthet Dent 2012;107:317-321.

27. Reich S, Petschelt A, Lohbauer U. The effect of finish line preparation and layer thickness on the failure load and fractography of $\mathrm{ZrO} 2$ copings. J Prosthet Dent 2008; 99:369-76.

28. Encke BS, Heydecke G, Wolkewitz M, Strub JR. Results of a prospective randomized controlled trial of posterior $\mathrm{ZrSiO}(4)$-ceramic crowns. J Oral Rehabil 2009;36:226-35.

29. Ortorp A, Kihl M, Carlsson G. A 3-year retrospective and clinical follow-up study of zirconia single crowns performed in a private practice. J Dent 2009;37:731-6.

30. Groten M, Huttig F. The performance of zirconium dioxide crowns: a clinical followup. Int J Prosthodont 2010; 23:429-31. 
31. Comlekoglu M, Dundar M, Ozcan M, Gungor M, Gokce $\mathrm{B}$, Artunc C. Influence of cervical finish line type on the marginal adaptation of zirconia ceramic crowns. Operative Dent 2009;34:586-92.

32. Shillinburg HT, Jacobi R \& Brackett SC, Quintessence Publ. Co. Chicago 1991

33. Rosentritt M. Plein T. Kolbeck C. Behr M. handel G.: Invitro fracture and marginal adaptation of ceramic crowns fixed on natural and artifical teeth .Int $\mathrm{J}$ Prosthodont 2000;13:387-391.

34. Alghazzawi TF, Lemons J, Liu P, Essig ME, Janowski GM, The failure load of CAD/CAM generated zirconia and glass-ceramic laminate veneers with different preparation designs, J Prosthet Dent 2012;108:386-393.

35. Gassino G, Barone Monfrin S, Scanu M, Spina G, Preti G. Marginal adaptation of fixed prosthodontics: a new in vitro 360-degree external examination procedure. Int J Prosthodont 2004;17:218-23.

36. Wolfart S, Wegner SM, Al-Halabi A, Kern M. Clinical evaluation of marginal fit of a new experimental all-ceramic system before and after cementation. Int $\mathrm{J}$ Prosthodont 2003;16:587-92.

37. Park SH. and Lee KB. A comparison of the fidelity between various cores fabricated with CAD/CAM system. J Kor Acad Prosthodont 2008; 43: 269-78.

38. Bosch G, Ender A, Mehl A. A 3-dimensional accuracy analysis of chairside CAD/CAM milling processes. $\mathrm{J}$ of prost dent 2014;1;112(6):1425-31.

39. Farid F, Hajimiragha H, Jelodar R, Mostafavi AS, Nokhbatolfoghahaie $\mathrm{H}$. In vitro evaluation of the effect of core thickness and fabrication stages on the marginal accuracy of an all-ceramic system. Journal of Dentistry (Tehran, Iran). 2012;9(3):188.

40. Effrosyni TA, Northeast SE, van Noort R. «Brittleness index of machinable dental materials and its relation to the marginal chipping factor.» $\mathbf{J}$ of dent 2007; 897-902.

41. Mormann WH, Stawarczyk B, Ender A, Sener B, Attin T, Mehl A. Wear characteristics of current aesthetic dental restorative $\mathrm{CAD} / \mathrm{CAM}$ materials: two-body wear, gloss retention, roughness and Martens hardness. J Mech Behav Biomed Mater 2013;20:113-125. 